\title{
Contribuições da Educação Não Formal para Educação Formal: Um Estudo de Visitas de Alunos da Educação Básica ao Departamento de Química da UFPR
}

Lucelena Fernanda Ferreira dos Santos

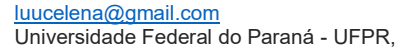

Curitiba, Paraná, Brasil

Leticia Leonardi Pedrosa

leticialeonardipedrosa@gmail.com

Universidade Federal do Paraná - UFPR, Curitiba, Paraná, Brasil

Joanez Aparecida Aires

joanez.ufpr@gmail.com

Universidade Federal do Paraná - UFPR, Curitiba, Paraná, Brasil

\section{RESUMO}

O objetivo desta pesquisa consistiu em investigar as implicações e contribuições de visitas escolares ao Departamento de Química da Universidade Federal do Paraná. A pesquisa foi realizada a partir de entrevistas com os alunos bolsistas e Tutoras do Programa de Educação Tutorial (PET-Química), provedores da atividade "Visita Orientada ao Departamento de Química na UFPR", uma professora regente de Química e três alunos do colégio visitante, além da aplicação de questionários para os demais alunos participantes da atividade. Os resultados apontam que as visitas motivam os participantes na compreensão de determinados conceitos da disciplina de química, facilitando o processo de assimilação do conteúdo através da relação teoria/prática. Um ponto importante foi a visita aos laboratórios de pesquisa do Departamento, onde os alunos ficaram deslumbrados com as pesquisas elaboradas dentro da universidade e sua relação com as aplicações no cotidiano, indo ao encontro da apropriação do conhecimento científico e inclusão social, citado por Marandino $(2005,2008)$. Por fim, esta pesquisa impulsionou a criação de um grupo de estudo no PET-Química/UFPR sobre educação não formal com o objetivo de melhoria das atividades desenvolvidas sobre o tema.

PALAVRAS-CHAVE: Educação em Química. Educação Não Formal. Programa de Educação Tutorial. 
Ao longo dos anos, o avanço da Ciência tem proporcionado variadas transformações na sociedade, desde o nível social, político e econômico, propiciando a evolução do ser humano (PINHEIRO, 2005). No âmbito das pesquisas sobre ensino de Ciências observa-se que este campo vem apresentando novas possibilidades para o processo ensino aprendizagem dos conceitos científicos. No entanto, no modelo de escola vigente, percebe-se que tais pesquisas causam pouco impacto, uma vez que neste, o ensino ainda é pautado em um letramento formal, no qual os alunos questionam e refletem pouco sobre os temas apresentados, tornando-os meros receptores de informação (VIEIRA; PEREIRA; MATOS, 2014).

Em vista disso, tem se intensificado a busca por novos espaços que proporcionem a interação entre o conteúdo teórico e a prática, com o objetivo de despertar nos estudantes o interesse pelo assunto visto em sala de aula. Estes espaços, tidos como não formais, podem compreender visitas a museus e parques de ciências, por exemplo, diversificando as fontes de conhecimento dos alunos e contribuindo para a sua formação acadêmica.

Segundo Montevechi (2005), a educação está inserida no cotidiano de um indivíduo, fazendo parte de uma relação que se estabelece na veiculação de informações, valores e atitudes de modo a construir uma percepção sobre o meio, contribuindo para a sociedade em que está inserido. Esta via é uma das principais encarregadas para a transmissão de cultura, sendo necessária uma manutenção constante do conteúdo que é passado à diante. Nesse sentido, a educação, via currículos escolares bem como, teorias de aprendizagem, sofrem modifiçções ao longo do tempo com o objetivo de que os sujeitos tenham acesso aos conhecimentos considerados válidos pela cultura na qual estão inseridos. Assim, pode-se concluir que há diversas formas de promover a educação, não havendo apenas um único modelo ou método educacional.

Partindo do pressuposto que a educação pode sofrer transformações e que as mesmas ocorrem em diferentes espaços de formação, como igrejas, espaços de lazer, família, etc., Afonso (apud MONTEVECHI, 2005) conceituou três modalidades educacionais, a saber: Educação Formal, Informal e Não formal.

A Educação Formal engloba toda uma estrutura sistemática de ensino disposto em ambientes escolares, como relata Montevechi (2005, p. 23): "Que tem como característica a difusão da cultura "universal" transmitida ao longo da história e condensada em currículos, através de conteúdos eleitos pelos seus dirigentes como importantes na formação do ser humano".

Essa forma de educação transmite a informação de modo organizado e sistemático, visando a aprendizagem por intermédio da reprodução dos conceitos aprendidos em sala. Tal sistema abrange todos os níveis educacionais (ensino básico escolar até o superior), de forma hierárquica e cronológica de conhecimento (COSTA, 2014).

Já a modalidade de Educação Informal compreende a transmissão do conhecimento através de uma veiculação não sistematizada, de forma mais espontânea. Isto significa que há a inclusão de conhecimentos, habilidades, valores e atitudes adquiridos ao longo da vida, por intermédio de estímulos recebidos pela experiência do cotidiano e influências e disponibilidade de recursos no ambiente em que o sujeito está inserido (COSTA, 2014). Esta forma educativa está presente 
em espaços como lares, igrejas, clubes e teatros, e outros meios de conhecimento, como jornais, revistas, livros, etc., onde cada indivíduo irá se desenvolver de acordo com o espaço que o mesmo teve acesso. De acordo com Brandão (apud MONTEVECHI, 2005, p. 22): "O espaço educacional não é escolar. Ele é o lugar da vida e do trabalho: a casa, o templo, a oficina, o barco, o mato, o quintal. Espaço que apenas reúne pessoas e tipos de atividade e onde o fazer faz o saber." Assim, essa estrutura educacional vem associada a outros objetivos educacionais, como entretenimento, lazer, expressão de afeto (MONTEVECHI, 2005), contribuindo para a formação intelectual e humana do indivíduo.

Por fim, a Educação Não Formal está assimilada a quaisquer atividades educacionais realizadas fora do ambiente escolar formal, de forma complementar e concordante ao último. Esse conceito de educação ainda apresenta divergências por parte de alguns autores, devido às inúmeras experiências vivenciadas em diversos espaços.

Os pensadores pioneiros a respeito deste tema foram Coombs, Prosser e Ahmed, na década de 70, para os quais a modalidade Não Formal inclui: "Componentes educacionais de programas projetados para atenderem a metas de desenvolvimento amplas, bem como a objetivos mais acadêmicos" (apud COSTA, 2014, p. 438).

As atividades aplicadas em espaços Não Formais devem ser organizadas e planejadas de modo a atender a necessidade de aprendizagem do aluno, utilizando de uma comunicação para atingir os objetivos educacionais e facilitar o entendimento do aluno. Por ser o foco deste trabalho, o estudo de espaços não formais será aprofundado adiante.

Como forma de sintetizar o assunto, as modalidades de educação foram dispostas a seguir em formato de imagem para melhor entendimento.

Figura 1 - Esquema de modalidades de educação: formal, não formal e informal

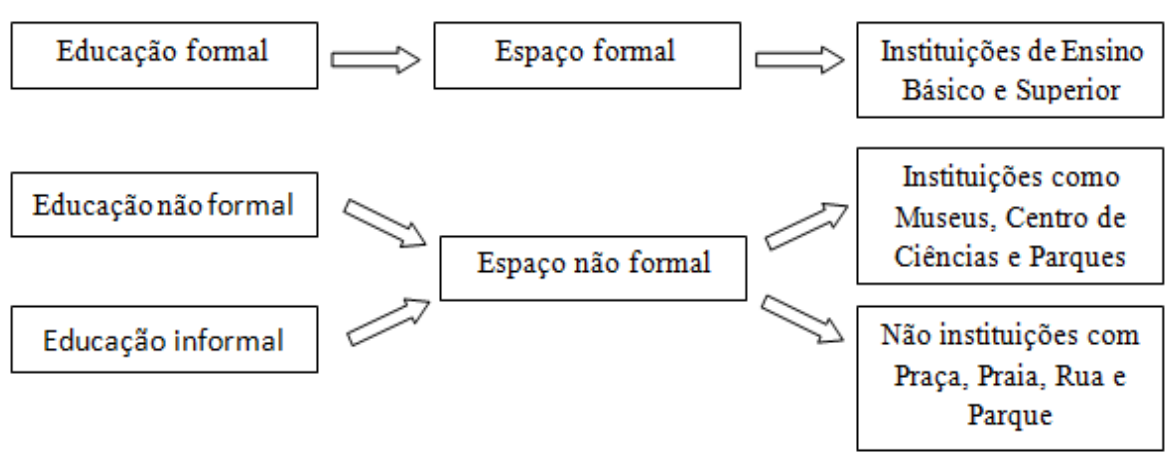

Fonte: Autoria própria (2017).

A educação não formal pode ser então compreendida como a ferramenta que proporciona a interação e aprendizagem entre os conteúdos trabalhados em sala de aula, ou seja, em espaços formais, com outros lugares de vivência dos alunos, como museus, teatros, etc. (BIANCONI; DIAS; VIEIRA, 2005). Esses espaços são organizados de forma que ocorra, de maneira intencional, a interação do visitante com o contexto do lugar, sendo um elemento importante na diferenciação entre educação formal e não formal. Além disso, o agente educador desta modalidade é 
o indivíduo responsável em orientar a visita, como o guia do espaço, por exemplo (GOHN, 2006).

Outras características, ressaltadas por Gohn (2006, p. 30), são apresentadas no seguinte trecho:

\begin{abstract}
A educação não formal tem outros atributos: ela não é, organizada por séries/idade/conteúdos; atua sobre aspectos subjetivos do grupo; trabalha e forma a cultura política de um grupo. Desenvolve laços de pertencimento. Ajuda na construção da identidade coletiva do grupo (este é um dos grandes destaques da educação não formal na atualidade). [...] Fundamenta-se no critério da solidariedade e identificação de interesses comuns e é parte do processo de construção da cidadania coletiva e pública do grupo.
\end{abstract}

Compreende-se também que a educação não formal não substitui a educação formal, pelo contrário, ela a complementa por meio da articulação da escola com os demais espaços da comunidade. Diante disso, a educação não formal produz como resultado uma sequência de ações na aprendizagem do indivíduo, tais como: a reformulação e construção de novas concepções de mundo; consciência e organização da forma de agir/comportar em grupos coletivos; contribuição para a formação de um sentimento de identidade com uma determinada comunidade; capacitar o indivíduo não apenas para o mercado de trabalho, mas também para a vida e suas adversidades; resgatar o sentimento de autovalorização, combate ao preconceito e luta por direitos, dentro de diferenças raciais, sociais, culturais; e aprendizagem a partir da prática, compreendendo o meio que o cerca (GOHN, 2006).

A Educação não formal se iniciou com os museus onde, segundo Allard e Boucher (apud MARANDINO, 2008), o desenvolvimento da função educativa dos museus está dividido em três etapas sucessivas. Sendo que primeira é marcada pela criação e inserção de museus em instituições de ensino formais, no caso, as universidades. Como exemplo temos o museu do Ashmolean Museum da Universidade de Oxford, criado em 1683, composto por coleções de história natural e geologia. A abertura do Ashmolean Museum marcou a origem dos museus públicos, foi nesse momento que grande maioria de colecionadores iniciaram as doações de suas coleções para o estado. Devido a isto foram abertos museus e coleções públicas estatais em diversos países da Europa (MARANDINO, 2008). Grande parte dos museus daquela época (que na Europa consistiu até o final do século XVIII) carregava aspectos próprios a uma instituição de pesquisa e se tornaram os grandes responsáveis pela organização de disciplinas científicas como a Geologia, Biologia e demais.

A segunda etapa foi marcada pela gradativa entrada de um público mais amplo nos museus, composto por diferenciadas classes sociais. Foi nos fins do século XVIII que o museu passou a ser tido como um lugar do saber e das artes, onde as variadas exposições eram contempladas pelos visitantes. O século XIX, também foi chamado de "século de ouro" dos museus, pois presencia a expansão destas instituições pelo mundo.

A Educação não formal no Brasil se inicia no período colonial histórico do Brasil, nos anos de 1500, com a entrada dos portugueses e até o ano de 1808, com a vinda da Família Real portuguesa ao país. Com a chegada da Realeza ao Brasil, as relações econômicas, sociais políticas e até mesmo as culturais se transformaram, de modo que o Brasil não fosse mais considerado uma colônia, mas sim como uma 
sede do reinado português (MONTEVECHI, 2005). No século XIX originaram-se os primeiros museus no país, sendo que o primeiro foi o Museu Real no Rio de Janeiro, construído em 6 de julho de 1808, que mais tarde se tornou o Museu Nacional. Foi este museu que influenciou na criação de novos museus como: Museu Paraense Emílio Goeldi criado em 1866 e localizado em Belém e o Museu Paranaense criado em 1883 em Curitiba.

A terceira etapa, segundo Allard e Boucher (apud MARANDINO, 2008) aconteceu ao longo do século XX. Devido ao aumento e diversificação do público, os museus não poderiam mais se contentar em apenas expor suas obras. Era necessário encontrar os meios para assegurar que os visitantes as entendessem e apreciassem. Os museus passaram a introduzirem estratégias que facilitassem a comunicação com os visitantes ao longo das exposições.

\section{PROGRAMA DE EDUCAÇÃO TUTORIAL - PET}

O Programa de Educação Tutorial (PET) foi criado em 1979 pela Coordenação de Aperfeiçoamento de Pessoal de Nível Superior (CAPES), onde fora denominado inicialmente de Programa Especial de Treinamento. O Programa tem como objetivo:

Promover a formação ampla e de qualidade acadêmica dos alunos de graduação envolvidos direta ou indiretamente com o programa, estimulando a fixação de valores que reforcem a cidadania e a consciência social de todos os participantes e a melhoria dos cursos de graduação (MOB, 1995, p. 7).

As atividades desenvolvidas pelo programa são pautadas na tríade: Ensino, Pesquisa e Extensão, de forma articulada, onde estas variam de acordo com cada grupo PET. Atividades como ministro de cursos e palestras, que atendam a comunidade acadêmica com temas que englobam diversos assuntos, visitas técnicas e projetos com o envolvimento da comunidade externa fazem parte dos inúmeros trabalhos desenvolvidos pelos PET's de todo o Brasil, onde atualmente, o programa conta com 842 grupos distribuídos entre 121 Instituições de Ensino Superior (BRASIL, 2006).

O grupo PET-Química da Universidade Federal do Paraná (UFPR) foi implementado em 1995 e conta com 14 integrantes, desenvolvendo atividades de cunho acadêmico, como minicursos, palestras e visitas à Indústrias Químicas, e extensão, com o recebimento de alunos de escolas públicas e particulares no Departamento de Química (DQ) da UFPR. Nessas visitas, os estudantes do ensino básico têm a oportunidade de conhecer a estrutura e funcionamento da Universidade, bem como os laboratórios de pesquisa e ensino presentes no DQ. Primeiramente, são realizados experimentos que abordam conteúdos de Química, como modelos atômicos, pH, tensão superficial e Química Orgânica, de modo a aproximar o que é visto em sala com a prática. Em seguida, os alunos são orientados na visita ao departamento, onde visitam salas de aula, laboratórios de ensino e de pesquisa, e nos arredores do campus, apresentando que a Universidade está aberta para recebê-los.

Dentre as atividades realizadas pelo grupo PET-Química, uma delas atua como Educação não formal, contribuindo para a Educação formal, onde aproxima-se os alunos de escola pública e privada, à Universidade. O grupo realiza visitas de alunos 
da Educação Básica ao Departamento de Química, possibilitando que estes conheçam a Universidade e presenciem a explicação e execução de experimentos realizados pelo grupo.

A Visita ao Departamento, como é conhecida a atividade, tem como objetivo promover a interação dos alunos da graduação com os alunos da Educação Básica e Professores das instituições de ensino, oferecendo a estes alunos a possibilidade de terem contato com a química prática, que muitas vezes não é vista por estes alunos. Os experimentos escolhidos para a realização da atividade são voltados aos conteúdos que estão sendo trabalhados em sala de aula, de modo que o aluno consiga relacionar com o que está aprendendo na Escola.

Vários são os trabalhos apresentados pelos grupos PET de todo o Brasil, então realizou-se uma pesquisa sobre os trabalhos voltados para a modalidade de Educação não formal. Estes trabalhos realizados por cada grupo são apresentados em encontros estaduais, regionais e nacionais dos grupos PET. Os títulos dos trabalhos encontrados, bem como os respectivos grupos e o evento que foram apresentados, estão presentes no Quadro 1.

Quadro 1 - Trabalhos apresentados pelos grupos PET que enquadram na modalidade de educação não formal

\begin{tabular}{|c|c|c|}
\hline Grupo & Evento/Ano & Título de Trabalho \\
\hline PET-Química & Enapet/2014 & $\begin{array}{c}\text { Recepção às escolas públicas: Oficina sobre } \\
\text { Química Forense }\end{array}$ \\
\hline PET-Química & Enapet/2014 & $\begin{array}{l}\text { Implicações da visita monitorada pelo } \\
\text { grupo PET-Química ao Departamento de } \\
\text { Química da UFPR na comunidade escolar }\end{array}$ \\
\hline PET-Biologia & Sulpet/2012 & $\begin{array}{l}\text { Atividade Assistencial: um complemento } \\
\text { diferenciado do desenvolvimento intra e } \\
\text { interpessoal }\end{array}$ \\
\hline PET-Agronomia & Sulpet/2012 & $\begin{array}{c}\text { Educação ambiental por meio de oficinas } \\
\text { de uma horta orgânica com alunos de } \\
\text { ensino médio do colégio SESI no município } \\
\text { de Marechal Cândido Rondon }\end{array}$ \\
\hline PET-Química & Sulpet/2012 & Grupo de Ação eu Adoro Química \\
\hline
\end{tabular}

Fonte: Autoria própria (2017).

\section{ATIVIDADES DESENVOLVIDAS PELO PET-QUÍMICA UFPR}

O grupo realiza diversas atividades levando em consideração a indissociabilidade entre ensino, pesquisa e extensão. Abaixo são citados alguns dos objetivos almejados ao se realizar tais atividades:

- A melhoria do curso de graduação ao qual o grupo está vinculado;

- A preparação dos alunos para atuar em seu futuro campo profissional;

- O desenvolvimento de competências básicas pelos integrantes do grupo no uso da linguagem escrita e oral, em idioma estrangeiro e na área de tecnologias de informação e comunicação;

- Promover uma formação acadêmica ética e cidadã de qualidade aos alunos; 
- Desenvolver o caráter multi e interdisciplinar nas atividades.

As atividades realizadas pelo grupo são:

- Jornal do Pet Química: Semestralmente os alunos integrantes do grupo realizam um jornal impresso composto por diversas seções, que englobam desde assuntos científicos como assuntos que não se restringem apenas a química. Este jornal inicialmente foi produzido em escala piloto para distribuição inicialmente aos acadêmicos da UFPR e posteriormente nas escolas públicas e privadas de ensino para divulgação científica.

- Mural do Pet Química: Semanalmente o mural é atualizado com notícias sobre os temas de educação, ciência e tecnologia e outros assuntos. Essas notícias são escolhidas pelos alunos mediante a leitura de jornais, revistas, sites e etc.

- Química na Escola: O grupo PET é responsável pelas visitas às escolas do ensino fundamental e médio em Curitiba. A atividade consiste em: uma apresentação contendo informações sobre a profissão do químico, realização de experimentos simples com explicações teóricas sobre os fenômenos e demonstração da sua relação ao cotidiano dos alunos e dar a oportunidade aos alunos de entrarem em contato com a química experimental.

- Visita orientada ao Departamento de Química: O grupo PET é responsável pelo agendamento e recepção dos estudantes dos ensinos fundamental e médio. A atividade é conduzida pelos estudantes do curso de química (PET e outros alunos da graduação que estiverem interessados). É desenvolvida para promover a interação entre os alunos da graduação e os alunos de escolas públicas e privadas, bem como a interação desses alunos com a Universidade. A atividade consiste na apresentação dos laboratórios do Departamento de Química e suas pesquisas, realização de experimentos e explicações, relacionando sempre com o cotidiano e aos assuntos que os estudantes visitantes estão trabalhando em sala de aula.

- Feira de profissões: O Curso de Química dispõe de um estande com experimentos e banners, onde os bolsistas PET e os demais estudantes voluntários nesta atividade atendem aos visitantes fornecendo informações sobre a química e o Curso de Química da UFPR.

- Visitas Técnicas: As visitas são agendadas pelos alunos do PET, com o objetivo de aproximar os acadêmicos do possível futuro campo profissional. Oferecendo a oportunidade para que o estudante conheça os processos industriais desenvolvidos na indústria e as atividades realizadas por um Químico em uma indústria química.

- Minicurso de Origin: O Programa Origin consiste em uma ferramenta muito utilizada para a plotagem de gráficos. Visando sua utilidade desde o início do curso de Química, e a dificuldade encontrada pelos alunos para entender o programa, o PET Química elaborou e realiza semestralmente um curso de 20 horas sobre a utilização do Origin.

\section{METODOLOGIA}

Nesta pesquisa as questões de investigação seguiram dois objetivos: 
a) investigar se os professores planejam e delimitam objetivos para a visita e se os explicitam claramente para os estudantes e;

b) de que forma os conhecimentos apreendidos durante as visitas foram consolidados pelos estudantes após a visita. Como realizado por Wolinski, Aires, Gloppo e Guimarães (2011), esta investigação inicialmente foi realizada uma entrevista com a professora que agendou e participou da visita, perguntamos brevemente algumas características da escola e o objetivo da visita ao Departamento de Química da UFPR. Em seguida, optamos por realizar entrevistas com: as tutoras atual e egressa do Programa de Educação Tutorial (TPET), com 5 (cinco) alunos integrantes do Programa (BPET), que acompanharam os alunos durante toda a visita. Posteriormente também foi decidido realizar entrevistas com uma amostra de 3 (três) alunos que participaram da visita (ARPE), e aplicar um questionário aos demais alunos participantes.

O primeiro objetivo foi avaliado de forma direta a partir das respostas obtidas nas entrevistas realizadas com professora do colégio visitante, das tutoras, dos integrantes do PET, e do entrecruzamento entre esses dados. O segundo foi avaliado de forma indireta a partir das respostas às questões 1 e 2 do questionário dos alunos (depois da visita), Figura 2, e de forma direta a partir das respostas dadas pelos 3 alunos visitantes entrevistados.

Figura 2 - Questionário aplicado aos alunos após a visita

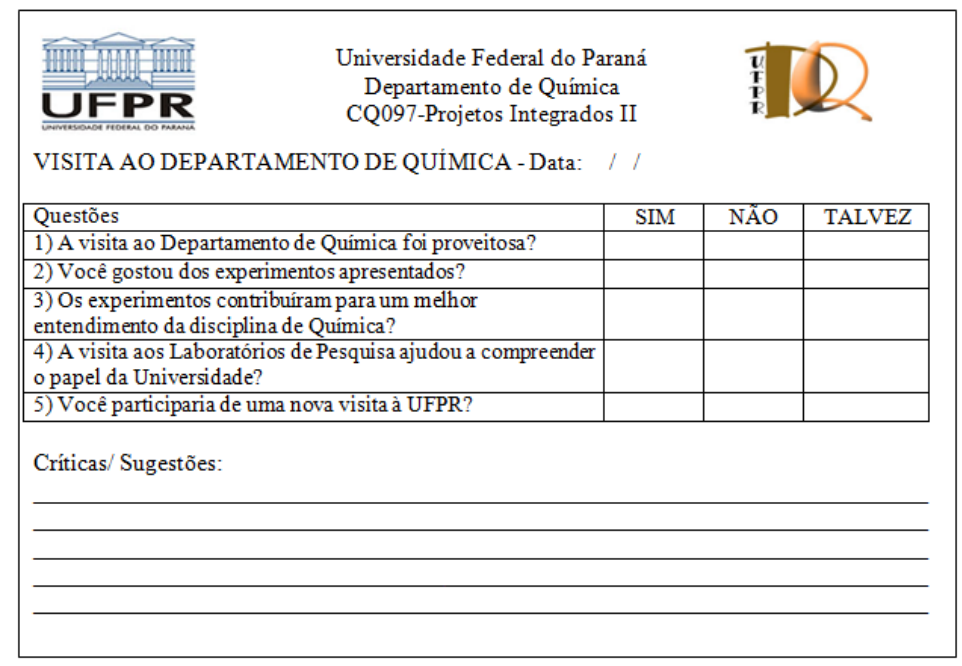

Fonte: Autoria própria (2017).

Assim, os resultados encontrados nas respostas dos questionários, bem como aqueles obtidos nas entrevistas realizadas serão discutidos a seguir.

\section{RESULTADOS E DISCUSSÕES}

Os resultados dos questionários aplicados aos alunos visitantes, e as entrevistas realizadas com os demais participantes serão apresentadas separadamente e então posteriormente os resultados serão confrontados.

Foi possível observar que os professores que buscam estas visitas orientadas, são professores interessados, que querem conhecer os experimentos e procuram a visita com o objetivo dos alunos aprenderem os conteúdos que estão sendo 
trabalhados, de forma mais dinâmica. Segundo o BPET1: "Eram professores interessados e buscavam um pouco da visita à universidade e conhecer os experimentos".

Os professores, também buscam trazer os alunos para a faculdade, de modo a incentivá-los a se tonarem futuros universitários, mostrando a eles que a Universidade não é algo tão distante.

Com relação aos experimentos que são realizados durante as visitas, notou-se que são experimentos destinados ao nível de ensino médio, que vão ao encontro com o que o professor está trabalhando em sala de aula e com o respectivo ano em que se encontra o aluno.

Segundo BPET2: "A gente procura experimento que seja a nível de ensino médio que vão ao encontro com o que se apresente em sala de aula".

Também foi citado durante as entrevistas, que os experimentos realizados são relacionados ao cotidiano dos alunos.

As visitas aos laboratórios de pesquisa são realizadas com o objetivo de mostrar aos alunos as pesquisas que são realizadas na Universidade, tentando aproximar a Pesquisa Acadêmica e esses alunos da educação básica. Essas visitas também são realizadas, com o intuito de estimular e aumentar o interesse dos alunos pela ciência, conforme dito por BPET5: "Acho que a maior tentativa é aproximar a universidade do aluno porque, muitas vezes, os alunos não sabem que são desenvolvidas pesquisas na universidade".

De acordo com as entrevistas realizadas, nota-se que as visitas são avaliadas por meio de questionários que são respondidos pelos alunos visitantes, e pelo retorno dado pelo professor regente da turma, que também acompanhou a visita. Segundo TPET2: "Normalmente o grupo PET sempre pede um retorno ao docente no sentido de poder avaliar e aprimorar este evento".

Com relação às entrevistas aplicadas aos alunos do colégio visitante, foram obtidas as seguintes respostas, apresentadas nos quadros 2 e 3 .

Quadro 2 - Respostas das perguntas 1, 2 e 3 realizadas anteriormente à visita

\begin{tabular}{c|c|c|c}
\hline \multirow{2}{*}{ Participantes } & $\begin{array}{c}\text { Participou } \\
\text { de outras } \\
\text { visitas? }\end{array}$ & $\begin{array}{c}\text { Conhecia } \\
\text { a UFPR? }\end{array}$ & $\begin{array}{c}\text { O que você esperava } \\
\text { dessa visita à UFPR? }\end{array}$ \\
\hline ARPE1 & Não & Sim & $\begin{array}{c}\text { Eu espero tirar as minhas } \\
\text { dúvidas sobre o curso de } \\
\text { química e acredito que } \\
\text { consegui. Eu gosto bastante } \\
\text { de química e escolhi o curso. }\end{array}$ \\
& Sim, ao museu & Sim & $\begin{array}{c}\text { Aprender a química na } \\
\text { prática, porque nós temos } \\
\text { só a parte teórica já que a } \\
\text { escola não tem recurso para } \\
\text { montar o laboratório. }\end{array}$ \\
\hline ARPE3 & Não & Sim & $\begin{array}{c}\text { Acho que conhecer o } \\
\text { ambiente da universidade e } \\
\text { os laboratórios. }\end{array}$ \\
\hline
\end{tabular}


Quadro 3 - Respostas das perguntas 1, 2 e 3 realizadas posteriormente à visita

\begin{tabular}{|c|c|c|c|}
\hline Participantes & $\begin{array}{l}\text { Os assuntos abordados } \\
\text { contribuíram para sua } \\
\text { aprendizagem? }\end{array}$ & $\begin{array}{l}\text { O que } \\
\text { mais lhe } \\
\text { chamou a } \\
\text { atenção? }\end{array}$ & $\begin{array}{l}\text { A visita despertou o } \\
\text { interesse em se } \\
\text { tornar um } \\
\text { Universitário? }\end{array}$ \\
\hline ARPE1 & $\begin{array}{l}\text { Sim, porque tinha assuntos } \\
\text { que eu nunca tinha visto } \\
\text { durante o ensino médio e lá } \\
\text { eu aprendi. }\end{array}$ & $\begin{array}{l}\text { Laboratório } \\
\text { de pesquisa. }\end{array}$ & $\begin{array}{c}\text { Sim, bastante. Eu } \\
\text { prestei vestibular esse } \\
\text { ano para o curso de } \\
\text { química e passei na } \\
\text { primeira fase. }\end{array}$ \\
\hline ARPE2 & $\begin{array}{c}\text { Sim. Como nós só } \\
\text { aprendemos na teoria, a } \\
\text { parte prática ajudou muito } \\
\text { na minha aprendizagem, } \\
\text { em como entender a } \\
\text { matéria. }\end{array}$ & $\begin{array}{l}\text { Laboratório } \\
\text { de pesquisa. }\end{array}$ & $\begin{array}{l}\text { Sim, com certeza. Eu } \\
\text { prestei vestibular para } \\
\text { educação física }\end{array}$ \\
\hline ARPE3 & $\begin{array}{l}\text { Sim. Eu fiquei mais } \\
\text { interessada nas aulas de } \\
\text { química e melhorou meu } \\
\text { rendimento, porque na } \\
\text { prática é muito diferente. }\end{array}$ & $\begin{array}{l}\text { Laboratório } \\
\text { de pesquisa. }\end{array}$ & $\begin{array}{c}\text { Sim, bastante. Eu } \\
\text { prestei vestibular para } \\
\text { direito. }\end{array}$ \\
\hline
\end{tabular}

Fonte: Autoria própria (2017).

Ao analisar as respostas dos alunos entrevistados, nota-se uma dificuldade em se encontrar um padrão entre as falas, visto o número pequeno de entrevistados coletados para a pesquisa. No entanto, pode-se observar que todos conheciam a UFPR, através de propagandas e redes sociais, e cada um possuía um respectivo objetivo para visita à Universidade.

Com relação à questão sobre os assuntos abordados durante a visita, os alunos responderam que a mesma contribuiu para a aprendizagem individual, sendo relatado que a prática (experimentos) ajudaram a facilitar a compreensão de certos conteúdos. Para representar tal conclusão, o excerto de ARPE3: "Sim. Como nós só aprendemos na teoria, a parte prática ajudou muito na minha aprendizagem, em como entender a matéria."

Um outro ponto em comum destacado durante a entrevista foi a notável admiração dos alunos pelos laboratórios de pesquisa, pois estes não conheciam as pesquisas que eram desenvolvidas no âmbito acadêmico. Essa parte da atividade, segundo Marandino (2005, p.162) "[...] é fundamental que se promova a apropriação desses conhecimentos pela população como forma de inclusão social."

Por fim, quando questionados sobre "se tornar um futuro universitário", ambos responderam que sim. Um reflexo dessas afirmações foi a participação de todos os entrevistados no Processo Seletivo da UFPR 2016/2017. 


\title{
SOBRE OS QUESTIONÁRIOS APLICADOS AOS ALUNOS DO ENSINO MÉDIO
}

Para atender todos os alunos visitantes, foram aplicados questionários ao final da visita para conhecer quais impressões obtidas ao final da atividade.

A aplicação de questionários é uma das diversas formas de obtenção de dados utilizadas para o estudo de determinada situação. O mesmo pode ser definido como:

\begin{abstract}
Técnica de investigação composta por um número mais ou menos elevado de questões apresentadas por escrito às pessoas, tendo por objetivo o conhecimento de opiniões, crenças, sentimentos, interesses, expectativas, situações vivenciadas, etc. (GIL apud CHAER; DINIZ; RIBEIRO, 2011).
\end{abstract}

Por ser um mecanismo de fácil acesso, que não abrange um elevado tempo e atinge a maioria da população em estudo, o mesmo fora selecionado. Para a sua aplicação com os alunos da escola visitante, foram elaboradas três perguntas onde as respostas poderiam ser "sim", "não" e "talvez". Além disso, o questionário continha um espaço reservado para críticas e sugestões.

Após a coleta de dados, a análise dos resultados fora realizada, onde as respostas obtidas pelos 18 questionários preenchidos se encontram no quadro abaixo.

Quadro 4 - Respostas dos questionários aplicados aos alunos visitantes

\begin{tabular}{c|c|c|c}
\hline Questões & SIM & NÃO & TALVEZ \\
\hline $\begin{array}{c}\text { 1) A visita ao departamento de Química } \\
\text { contribuiu para sua aprendizagem? }\end{array}$ & 16 & 2 & - \\
\hline $\begin{array}{c}\text { 2) Os experimentos realizados aqui na UFPR } \\
\text { contribuíram para um melhor entendimento da } \\
\text { disciplina de Química na escola? }\end{array}$ & 14 & 1 & 3 \\
\hline $\begin{array}{c}\text { 3) Você gostaria de participar de uma outra } \\
\text { atividade de aprendizagem fora da escola? }\end{array}$ & 16 & 1 & 1 \\
\hline
\end{tabular}

Fonte: Autoria própria (2017).

Para melhor compreensão dos resultados, as respostas de cada questão se encontram em forma de gráfico, como visto na figura 3. 
Figura 3 - Representação gráfica dos resultados obtidos nos questionários

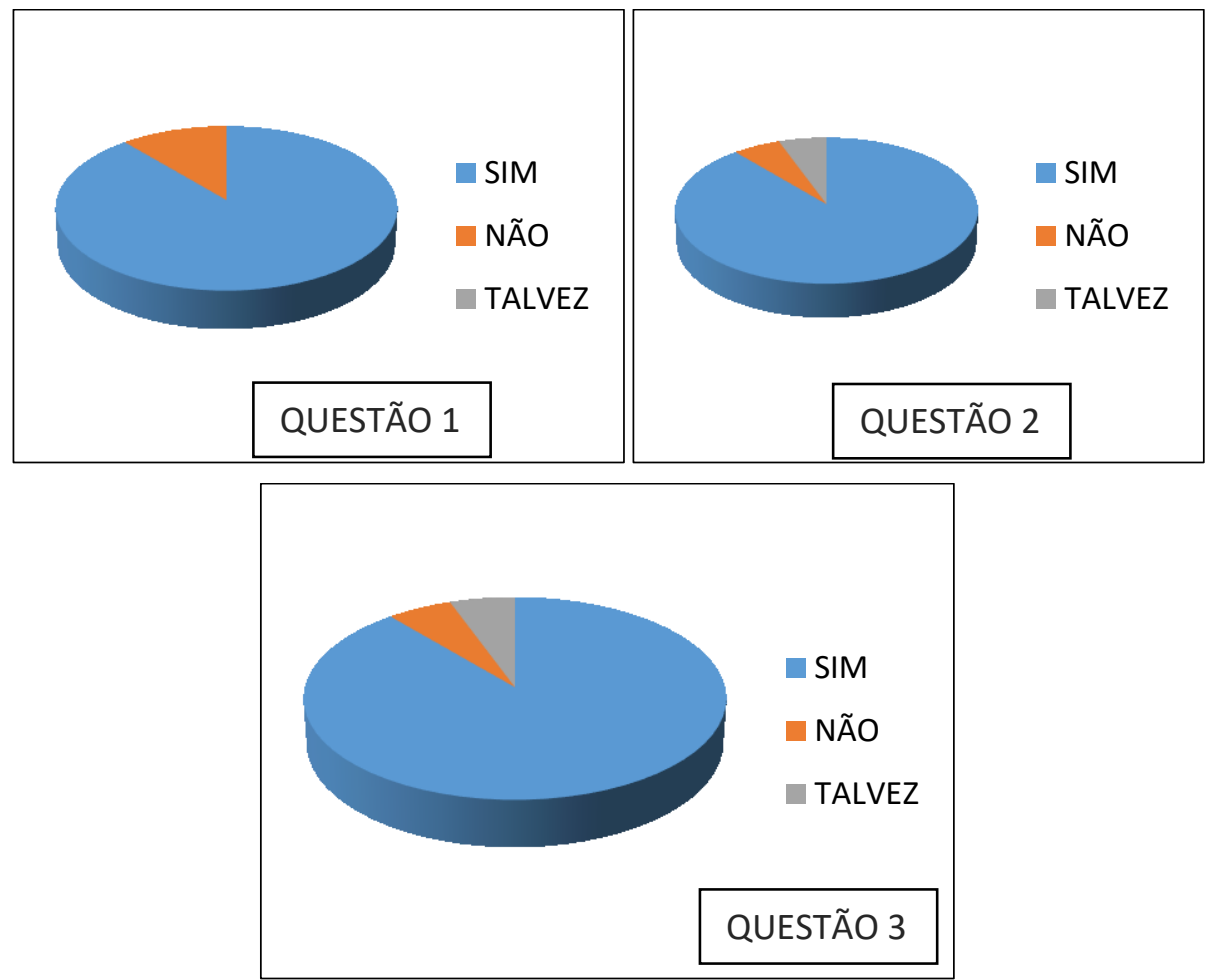

Fonte: Autoria própria (2017).

Para questão 1, intitulada "a visita ao departamento de Química contribuiu para sua aprendizagem?", a maior parte das respostas encontradas (16 "sim", 1 "não" e 1 "talvez") nos questionários concordam que a atividade "Visita ao Departamento de Química da UFPR" contribuiu para a aprendizagem individual do indivíduo em relação à disciplina de química. Essa aprendizagem compreende os conhecimentos obtidos ao longo da visita, tais como a realização de pesquisas científicas e a relação existente entre a química apresentada em sala de aula com a produzida em um laboratório, por exemplo.

Para a questão 2 denominada "os experimentos realizados aqui na UFPR contribuíram para um melhor entendimento da disciplina de Química na escola?" apresentou, em sua grande maioria, resultados positivos (14 "sim", 1 "não" e 3 "talvez"). A apresentação de experimentos relacionados ao cotidiano do aluno facilitou a associação do mesmo com os estudos realizados em sala de aula. Além disso, apenas o fato de ter o contato com novas metodologias, como o emprego de experimentos, já é um fato importante, pois muitos alunos visitantes relataram que nunca participaram de alguma atividade de mesma natureza durante as aulas ou no próprio laboratório da escola. Com isso, nota-se que a realização de experimentos que questione o aluno a respeito das ações/reações que ocorrem durante a sua realização e que façam parte do seu cotidiano é possível "estreitar o elo entre motivação e aprendizagem, [...] o envolvimento dos alunos seja mais vívido e acarrete resultados positivos na evolução do conhecimento" (JÚNIOR, 2008).

Por fim, a questão 3 "você gostaria de participar de uma outra atividade de aprendizagem fora da escola?" também apresenta resultados positivos, sendo 16 "sim", 1 "não" e 1 "talvez". Esse fato indica que ambientes não formais de ensino, 
como museus e até mesmo a universidade, pode ser um espaço de conhecimento para o aluno visitante, uma vez que difere da realidade vivida pelo mesmo. Durante a visita, alguns alunos relataram para os estudantes bolsistas do PET que nunca participaram de visitas aos outros espaços diferentes do ambiente escolar ao longo do ano. É importante ressaltar que nesse ponto existem diversos fatores envolvidos que possam inviabilizar uma visita ao outro espaço, como o agendamento de transporte e disponibilidade de horário durante o calendário escolar, por exemplo.

\section{SOBRE AS RESPOSTAS DA PROFESSORA REGENTE DE QUÍMICA}

Após a realização da entrevista antes da visita, com a docente regente de Química que acompanhou a atividade, as respostas obtidas foram apresentadas de forma simplificada no Quadro 5:

Quadro 5 - Resposta da pergunta realizada para a professora regente de química ( $P R Q$ ) antes da atividade

\begin{tabular}{c|c}
\hline Como conheceu a atividade? & Antes da visita \\
\hline Através de outros professores. & $\begin{array}{c}\text { Fazer nossos alunos conhecer a realidade de uma } \\
\text { universidade e despertar o interesse a disciplina de } \\
\text { química, mostrando a importância da mesma no } \\
\text { cotidiano de cada um deles. }\end{array}$ \\
\hline
\end{tabular}

Fonte: Autoria própria (2017).

Com relação às repostas obtidas posteriormente a visita, as mesmas se encontram no Quadro 6 a seguir:

Quadro 6 - Resposta das perguntas realizadas para a professora regente de química (PRQ) depois da atividade

\begin{tabular}{|c|c|c|c|}
\hline \multicolumn{4}{|c|}{ Depois da visita } \\
\hline $\begin{array}{l}\text { Expectativas } \\
\text { atendidas? }\end{array}$ & $\begin{array}{l}\text { Contribuição para a } \\
\text { aprendizagem dos } \\
\text { alunos? }\end{array}$ & $\begin{array}{l}\text { A visita auxiliou na } \\
\text { compreensão da } \\
\text { pesquisa realizada na } \\
\text { universidade? }\end{array}$ & $\begin{array}{c}\text { Alcançou os } \\
\text { objetivos iniciais? }\end{array}$ \\
\hline Sim. & $\begin{array}{l}\text { Através dessa } \\
\text { oportunidade, } \\
\text { conseguiram unir a teoria } \\
\text { em sala de aula com a } \\
\text { prática e visualizarem } \\
\text { com mais facilidade todo } \\
\text { o conteúdo abordado. }\end{array}$ & $\begin{array}{l}\text { Auxiliou demais, } \\
\text { porque muitos } \\
\text { alunos têm uma } \\
\text { imagem distorcida da } \\
\text { nossa disciplina, não } \\
\text { percebendo a } \\
\text { importância da } \\
\text { química no nosso dia- } \\
\text { a-dia. }\end{array}$ & $\begin{array}{c}\text { Sim. Equipe PET, } \\
\text { muito } \\
\text { comprometida, } \\
\text { clara e objetiva. } \\
\text { Demonstrou a } \\
\text { importância da } \\
\text { união teoria- } \\
\text { prática, despertou } \\
\text { curiosidade e } \\
\text { interesse em } \\
\text { nossos alunos. }\end{array}$ \\
\hline
\end{tabular}


Como relatado na entrevista, a docente buscou a atividade "Visita ao Departamento de Química na UFPR" com indicação de outros professores que já participaram ou tinham conhecimento da realização da visita. Ao agendar a visita, os objetivos pré-estabelecidos para essa atividade eram "Fazer nossos alunos conhecer a realidade de uma universidade e despertar o interesse a disciplina de química, mostrando a importância da mesma no cotidiano de cada um deles" (PRQ).

Nota-se que existe uma motivação por parte da docente em apresentar a importância da disciplina no cotidiano, isto é, contextualizá-la. Esse processo de contextualização é definido por Silva $(2007$, p. 10) como sendo "[...]um modo de ensinar conceitos das ciências ligados à vivência dos alunos, seja ela pensada como recurso pedagógico ou como princípio norteador do processo de ensino".

Esse processo pode ser realizado tanto durante as aulas de química quanto em outros espaços fora da escola. Além de promover a relação teoria/prática, a visita também abrange a visualização da "vida universitária", aproximando o aluno da escola pública da realidade do mundo acadêmico, que também pode ser alcançado pelo mesmo, como destacado por Silva (2007, p. 19): "Uma característica marcante da utilização de aspectos do cotidiano no ensino de Química é a crença no potencial motivacional, ou seja, situações do cotidiano, quando exemplificadas, servem para motivar o aluno a aprender".

Com relação às respostas obtidas após a visita pelo departamento e laboratórios de pesquisas, a docente relatou que a atividade contribuiu para "unir a teoria em sala de aula com a prática e visualizarem com mais facilidade todo o conteúdo abordado" (PRQ). De forma análoga, outra resposta apresentada pela docente sobre a compreensão por parte dos alunos a respeito das pesquisas realizadas no âmbito acadêmico, auxiliou na reconstrução da imagem da importância da química em todos os processos, uma vez que a partir da atividade os alunos "ficaram muito mais interessados e mudaram a concepção da Química"(PRQ).

Por fim, a docente conclui que conseguiu atingir os objetivos da visita, bem como parabenizou o PET-Química pela iniciativa em realizar atividades com essa temática.

\section{CONSIDERAÇÕES FINAIS}

Nesta pesquisa buscamos avaliar as contribuições e implicações das visitas escolares ao Departamento de Química na UFPR. Para isso, foram realizadas entrevistas e aplicações de questionários para os participantes da atividade "Visita Orientada ao Departamento de Química". Tendo por base nossos achados e reflexões, consideramos que para o ensino de Ciências, a modalidade de educação não formal a qual pode se dar por meio de visitas realizadas fora do ambiente escolar, pode se constituir em uma importante e diversificada fonte de conhecimento para os alunos.

Ao analisar os resultados obtidos, observamos que inserir o aluno do ensino básico em um ambiente não formal como meio de aprendizagem, pode, além de motivar, contribuir para a compreensão de determinados conceitos, facilitando o processo de assimilação do conteúdo. Muitos alunos relataram que após a visita, 
os conteúdos da disciplina de química ficaram mais claros, uma vez que ocorreu a junção da teoria trabalhada em sala de aula com a prática (experimentos).

Quando comparado a outros trabalhos, como de Wolinski, Aires, Gloppo e Guimarães (2011), nota-se que nesta visita, a docente regente de Química possuía objetivos claros com relação à visita ao Departamento de Química. Isto é, a atividade não foi vista como um momento de lazer e descontração, mas sim uma oportunidade de relacionar o conteúdo trabalhado em sala de aula em outro ambiente, tido como 'não formal', o que consideramos o que pode ser já um avanço na compreensão das potencialidades da educação não formal por parte dos professores, uma vez que que aquela pesquisa foi realizada em 2010.

Um outro ponto importante foi a citação da visita aos laboratórios de pesquisa do Departamento, que era um ambiente desconhecido pelos alunos visitantes. Muitos ficaram deslumbrados com as pesquisas elaboradas dentro da universidade e sua relação com as aplicações no dia-a-dia, como produtos utilizados pela sociedade, indo ao encontro da apropriação do conhecimento científico pela população como forma de inclusão social, citado por Marandino.

Por fim, concluímos que os objetivos desta pesquisa foram alcançados, bem como também auxiliaram na expansão das atividades desenvolvidas pelo Programa de Educação Tutorial (PET-Química). O resultado foi a criação de um grupo de estudo a respeito da educação não formal, visando a melhoria das atividades e ampliação dos conhecimentos sobre o tema. 


\title{
Contributions of Non-formal Education to Formal Education: A Study of Visits of Basic Education Students to the Department of Chemistry at UFPR
}

\begin{abstract}
The objective of this research was to investigate the implications and contributions of school visits to the Chemistry Department of the Federal University of Paraná. The research was carried out from interviews with the scholarship students and Tutorials of the Tutorial Education Program (PET-Química), providers of the activity "Visit Oriented to the Department of Chemistry at UFPR", a professor of chemistry and three students of the visiting college, besides the application of questionnaires to the other students participating in the activity. The results point out that the visits motivate the participants to understand certain concepts of the chemistry discipline, facilitating the process of assimilation of content through the relation theory / practice. An important point was the visit to the Department's research laboratories, where students were dazzled by the research developed within the university and its relation with the applications in the daily life, going towards the appropriation of scientific knowledge and social inclusion, cited by Marandino, Theoretical reference used. Finally, this research led to the creation of a study group on non-formal education by PET-Química in order to improve the activity and increase knowledge about the subject.
\end{abstract}

KEYWORDS: Education in Chemistry. Non-Formal Education. Tutorial Education Program. 


\section{REFERÊNCIAS}

BIANCONI, M. L.; DIAS, M.; VIEIRA, V. Espaços Não-formais de Ensino e o Currículo de Ciências. Ciência e Cultura, v. 57, n.4, 2014, p. 21.

BRASIL. Ministério da Educação. Manual de Orientações Básicas do PET. Disponível em:

<http://portal.mec.gov.br/index.php?option=com_docman\&view=download\&ali as=338-manualorientabasicas\&category_slug=pet-programa-de-educacaotutorial\&Itemid=30192>. Acesso em: 05 Jun. 2016.

CHAER, G.; DINIZ, R. R. P.; RIBEIRO, E. A. A técnica do questionário na pesquisa educacional. Evidências, v. 7, n. 7, p. 251-266, 2011.

COSTA, R. H. Notas sobre a Educação Formal, Não Formal e Informal. In: Simpósio Brasileiro de Pós Graduandos em Música, III, 2014, Rio de Janeiro. Anais... Rio de Janeiro, 2014.

GOHN, M. G. Educação não formal, participação da sociedade civil e estruturas colegiadas nas escolas. Ensaio: Avaliação e Políticas Públicas em Educação, v. 14, n. 50,2006, p. $27-38$.

JÚNIOR, W. E. F. Uma Abordagem Problematizadora para o Ensino de Interações Intermoleculares e Conceitos Afins. Química Nova na Escola, n. 29, 2008, p. 2023.

MARANDINO, M. Educação em Museus: a mediação em foco. USP: 2008. . A Pesquisa Educacional e a Produção de Saberes no Museu de Ciência. Revista História, Ciência e Saúde, v. 12, 2005, p. 161 - 181.

MONTEVECHI, W. R. A. Educação Não Formal no Brasil: 1500-1808. 2005. 131 f. Dissertação (Mestrado em Educação) - Centro Universitário Salesiano de São Paulo, São Paulo. 2005.

MORAES, R; GALIAZZI, M. do C. Análise Textual Discursiva. 2ą. ed. ljuí: Unijuí. 2003.

Análise Textual Discursiva: Processo Reconstrutivo De Múltiplas

Faces. Ciência e Educação. v. 12, n. 1, 2006, p. 117-128. 
PINHEIRO, N. A. M. Educação Crítico-Reflexiva para um Ensino Médio CientíficoTecnológico: A Contribuição do Enfoque CTS para o Ensino-Aprendizagem do Conhecimento Matemático. 2005. 306 f. Tese (Doutorado em Educação Cientifica e Tecnológica) - Universidade Federal de Santa Catarina, Florianópolis. 2005.

SILVA, E. L. Contextualização no Ensino de Química: ideias e proposições de um grupo de professores. 2007. 144 f. Dissertação (Mestrado em Ensino de Ciências) - Universidade de São Paulo, São Paulo. 2007.

VIEIRA, G. Q.; PEREIRA, L. P.; MATOS, W. R. Avaliação de espaços não formais de educação para o ensino de ciência: estudo de caso do Museu Ciência e Vida, Duque de Caixias, RJ. Almanaque Multidisciplinar de Pesquisa, Rio de Janeiro, v. 1, n. 2, 2014. Disponível em:

$<$ http://publicacoes.unigranrio.edu.br/index.php/amp/article/viewFile/2458/133 4>. Acesso em: 22 mai. 2016.

WOLINSKI, A. E.; AIRES, J.; GLOPPO, C.; GUIMARÃES, O. Por que Foi Mesmo que a Gente Foi Lá? Uma Investigação sobre os Objetivos dos Professores ao Visitar o Parque da Ciência Newton Freire-Maia. Química Nova na Escola, v.33, n.2, 2011. Disponível em: <http://qnesc.sbq.org.br/online/qnesc33_3/142-EA06509.pdf>. Acesso em: 16 nov. 2016.

Recebido: 29 mai. 2017

Aprovado: 29 ago. 2017

DOI: 10.3895 /actio.v2n1.6804

Como citar:

SANTOS, L. F. F.; AIRES, J. A.; PEDROSA, L. L. Contribuições da Educação Não Formal para Educação Formal: Um Estudo de Visitas de Alunos da Educação Básica ao Departamento de Química da UFPR. ACTIO, Curitiba, v. 2, n. 1, p. 456-473, jan./jul. 2017. Disponivel em: <https://periodicos.utfpr.edu.br/actio>. Acesso em: XXX.

Correspondência:

Lucelena Fernanda Ferreira dos Santos

Rua Antônio Brandalize, 197, Casa 3, Curitiba, Paraná, Brasil.

Direito autoral: Este artigo está licenciado sob os termos da Licença CreativeCommons-Atribuição 4.0

Internacional.

(c) (1) 